\title{
HLA-Antigens and Diabetic Retinopathy: A Different View Warranted
}

Sir,

In their recent publication [1], Deckert et al. of Denmark who deal mainly with aspects of basement membrane thickening in longterm type 1 diabetics, also present results of HLA-typing in a rather small sample of 36 patients 15 of whom had proliferative retinopathy. No statistically different HLA-patterns were found between subjects with and without proliferative retinopathy and it was stated that "considering all available data, there is at present no evidence that HLA is involved in the susceptibility to retinopathy once insulin-dependent diabetes has developed. Accordingly, the genetic background for the development of this complication [2] probably involves non-HLA genes."

Since this matter is, of course, of considerable clinical interest we would like to draw attention to observations which seem to contradict this statement, and which we have made in a somewhat larger group $(n=62)$ of type 1 diabetics (onset of the disease below the age of 30 years) in southern Germany, although more patients will be examined before final conclusions are reached. Fundus photography and fluorescence angiography were performed in each subject in addition to fundoscopy (in contrast to the study of Deckert et al); diabetic retinopathy was graded from 0 to III following the classification of Ballantyne. Subjects without retinopathy or with grade I retinopathy were only included in the study if their diabetes had lasted more than 5 , or more than 10 years respectively, in order to select a group of patients with a more "benign" course of retinopathy and compare it with groups suffering from more severe retinopathy. By these criteria the "benign" group consisted of 28 subjects, 22 patients had more severe (grade II) background retinopathy and 12 proliferative (grade III) retinopathy. Mean duration of diabetes $(14 \pm 1,16 \pm 1$ and $19 \pm 2$ years) did not differ significantly except between the "benign" versus the proliferative group $(\mathrm{p}<0.02)$. Results on HLA-B-antigens typical for type 1 diabetes are summarized in Table 1.
As may be seen a more subtle view of the possible association of diabetic retinopathy with the HLAsystem seems to be warranted. Comparing subjects with "benign" course of retinopathy and those with more severe background retinopathy, B-8-positivity more than doubled in this latter group whereas B-18subjects appeared to be relatively protected against grade II retinopathy. As far as proliferative retinopathy is concerned we would generally agree with Deckert et al. that such patients do not show different frequencies of HLA-B-antigens typical for type 1 diabetes when compared to subjects with "benign" course of retinopathy, although interestingly enough there was only one B-18-positive subject in the proliferative group. It is noteworthy in this context that in the Danish study as well, in contrast to $28.6 \%$ of subjects with benign nonproliferative retinopathy, only two individuals with proliferative retinopathy were B-18-positive, both of whom were B-15-carriers as well.

If one would allow combination of the Danish and our data, raising e.g. the "benign" group to 49 individuals and comparing this group with our group of patients with more severe background retinopathy, the same differences for B- 8 and B-18 as in our study alone would become apparent.

Table 1. Frequencies of HLA-B 8, -B15, and -B 18 in type 1 diabetics with "benign" course of retinopathy (no retinopathy after more than 5 , or only grade I retinopathy after more than 10 years of diabetes), with more severe (grade II) background retinopathy and with proliferative (grade III) retinopathy

\begin{tabular}{|c|c|c|c|c|}
\hline \multirow[b]{2}{*}{ Retinopathy } & \multicolumn{4}{|c|}{ Frequencies in $\%$} \\
\hline & $\begin{array}{l}\text { "Benign" } \\
(n=28)\end{array}$ & $\begin{array}{l}\text { Mor } \\
\text { (gra } \\
\text { bacl } \\
(\mathrm{n}=\end{array}$ & $\begin{array}{l}\text { e severe } \\
\text { de II) } \\
\text { ground } \\
=22 \text { ) }\end{array}$ & $\begin{array}{l}\text { Proliferative } \\
\text { (grade III) } \\
(\mathrm{n}=12)\end{array}$ \\
\hline B-8 & \multicolumn{2}{|c|}{$28.6 \ldots \mathrm{p}<0.02$} & 63.6 & 41.7 \\
\hline B- 15 & \multicolumn{3}{|l|}{32.1} & 16.7 \\
\hline B-18 & \multicolumn{3}{|c|}{$25.0 \ldots \mathrm{p}<0.015 \quad 0$} & 8.8 \\
\hline
\end{tabular}


Finally it should be said that studies like ours do not challenge the benefit to be gained from good metabolic control in combatting the problem of retinopathy in diabetic subjects, since the HLA-pattern seems not to be of predictive value in the individual case. However, it seems warranted to investigate further, with sound ophthalmological methods, whether the progression of diabetic retinopathy is modified to a certain degree on a genetic basis, perhaps in relation to the major histocompatibility complex as represented by the HLA-system, particularly as far as the more severe type of background retinopathy is concerned.

Yours etc.

E. Standl, T. Dexel, T. Lander, E. D. Albert, and S. Scholz

\section{References}

1. Deckert T, Egeberg J, Frimodt-Møller C, Sander E, Svejgaard A (1979) Basement membrane thickness, insulin antibodies and HLA-antigens in long standig insulin dependent diabetics with and without severe retinopathy. Diabetologia 17: 91-96

2. Pyke D A, Tattersall R B (1973) Diabetic retinopathy in identical twins. Diabetes 22: 613-618

E. Standl, M. D.

Diabetes Research Unit and

III ${ }^{\text {rd }}$ Medical Department

City Hospital Schwabing

Kölner Platz 1

D-8000 München 40

Federal Republic of Germany 